\title{
Rationale for graft selection in patients with complex internal carotid artery aneurysms treated with extracranial to intracranial high-flow bypass and therapeutic internal carotid artery occlusion
}

\author{
Hidetoshi Matsukawa, MD, PhD, ${ }^{1}$ Shiro Miyata, MD, PhD, ${ }^{1}$ Toshiyuki Tsuboi, MD, PhD, ${ }^{1}$ \\ Kosumo Noda, MD, ${ }^{1}$ Nakao Ota, MD, ${ }^{1}$ Osamu Takahashi, MD, MPH, PhD, ${ }^{2}$ Rihee Takeda, MD, ${ }^{1}$ \\ Sadahisa Tokuda, MD, ${ }^{1}$ Hiroyasu Kamiyama, MD, ${ }^{1}$ and Rokuya Tanikawa, MD ${ }^{1}$ \\ 'Department of Neurosurgery, Stroke Center, Teishinkai Hospital, Sapporo; and ${ }^{2}$ Center for Clinical Epidemiology, Internal \\ Medicine, St. Luke's International Hospital, Tokyo, Japan
}

\begin{abstract}
OBJECTIVE After internal carotid artery (ICA) sacrifice without revascularization for complex aneurysms, ischemic complications can occur. In addition, hemodynamic alterations in the circle of Willis create conditions conducive to the formation of de novo aneurysms or the enlargement of existing untreated aneurysms. Therefore, the revascularization technique remains indispensable. Because vessel sizes and the development of collateral circulation are different in each patient, the ideal graft size to prevent low flow-related ischemic complications (LRICs) in external carotid artery (ECA)-middle cerebral artery (MCA) bypass with therapeutic ICA occlusion (ICAO) has not been well established. Authors of this study hypothesized that the adequate graft size could be calculated from the size of the sacrificed ICA and the values of MCA pressure (MCAP) and undertook an investigation in patients with complex ICA aneurysms treated with ECA-graft-MCA bypass and therapeutic ICAO.
\end{abstract}

METHODS In the period between July 2006 and January 2016, 80 patients with complex ICA aneurysms were treated with ECA-MCA bypass and therapeutic ICAO. Preoperative balloon test occlusion (BTO) was performed, and the BTO pressure ratio was defined as the mean stump pressure/mean preocclusion pressure. Low flow-related ischemic complications were defined as new postoperative neurological deficits and ipsilateral cerebral blood flow reduction. Initial MCAP (iMCAP), MCAP after clamping the ICA (cMCAP), and MCAP after releasing the graft (gMCAP) were intraoperatively monitored. The MCAP ratio was defined as gMCAP/iMCAP. Based on the Hagen-Poiseuille law, the expected MCAP ratio ([expected gMCAP]/iMCAP) was hypothesized as follows: (1 - cMCAP/iMCAP)(graft radius//CA radius) ${ }^{2}$ + (cMCAP/iMCAP). Correlations between the BTO pressure ratio and CMCAP/iMCAP, and between the actual and expected MCAP ratios, were evaluated. Risk factors for LRICs were also evaluated.

RESULTS The mean BTO pressure ratio was significantly correlated with the mean cMCAP/iMCAP $(r=0.68, p<$ 0.0001). The actual MCAP ratio correlated with the expected MCAP ratio $(r=0.43, p<0.0001)$. If the expected MCAP ratio was set up using the BTO pressure ratio instead of CMCAP/iMCAP (BTO-expected MCAP ratio), the mean BTO-expected MCAP ratio significantly correlated with the expected MCAP ratio $(r=0.95, p<0.0001)$. During a median followup period of 26.1 months, LRICs were observed in 9 patients (11\%). An actual MCAP ratio $<0.80(p=0.003)$, expected MCAP ratio $<0.80(p=0.001)$, and $\left(M_{2} \text { radius/graft radius }\right)^{2}<0.49(p=0.002)$ were related to LRICs according to the Cox proportional-hazards model.

CONCLUSIONS Data in the present study indicated that it was important to use an adequate graft to achieve a sufficient MCAP ratio in order to avoid LRICs and that the adequate graft size could be evaluated based on a formula in patients with complex ICA aneurysms treated with ICAO.

https://thejns.org/doi/abs/10.3171/2016.11.JNS161986

KEY WORDS complex aneurysm; formula; high-flow bypass; selection of the graft; vascular disorders

ABBREVIATIONS BTO = balloon test occlusion; CTA = CT angiography; DWI = diffusion-weighted imaging; ECA = external carotid artery; ICA = internal carotid artery; $I C A O=I C A$ occlusion; $C M C A P=$ MCAP after temporarily clamping the ICA; gMCAP = MCAP after releasing the graft bypass; iMCAP = initial MCAP; $L R I C=$ Iow flow related ischemic complication; $\mathrm{MCA}=$ middle cerebral artery; $\mathrm{MCAP}=\mathrm{MCA}$ pressure; $\mathrm{mRS}=$ modified Rankin Scale; RA = radial artery; STA = superficial temporal artery; SV = saphenous vein

SUBMITTED July 30, 2016. ACCEPTED November 17, 2016.

INCLUDE WHEN CITING Published online June 2, 2017; DOI: 10.3171/2016.11.JNS161986. 
$\mathrm{T}$ REATMENT for complex internal carotid artery (ICA) aneurysms often requires permanent ICA occlusion (ICAO). Although most patients tolerate the loss of one ICA just after the operation, a significant percentage suffer either immediate or delayed neurological deficits related to poor collateral circulation. ${ }^{4}$ Preoperative balloon test occlusion (BTO) of the ICA is frequently performed to simulate the ischemic condition caused by ICAO; however, the test can sometimes produce false-negative findings, and ischemic surgical complications can subsequently develop. In fact, delayed ischemic complications can occur in $10 \%$ of patients who pass the BTO with hypotensive challenge. . $^{134,52}$ In addition, after ICAO without revascularization, hemodynamic alterations will occur in the circle of Willis with increased flow over the contralateral ICA. These hemodynamic changes create conditions conducive to the formation of de novo aneurysms or the enlargement of existing untreated aneurysms, exposing the patient to a risk of subarachnoid hemorrhage. . $^{8,10,14,16,59}$ Therefore, physicians implement cerebral revascularization strategies using the external carotid artery (ECA)graft-middle cerebral artery (MCA) bypass when therapeutic ICAO is needed.

Because the vessel size of the sacrificed ICA and the development of collateral circulation are different in each patient, the ideal graft size to prevent low flow-related ischemic complications (LRICs) in ECA-MCA bypass has not been well established. Our recent studies have shown that intraoperative MCA pressure (MCAP) can be used as a surrogate measure of regional cerebral perfusion pressure and that MCAPs have an impact on LRICs in complex ICA aneurysms treated with ECA-graft-MCA bypass and therapeutic ICAO. ${ }^{39,40}$

We hypothesized that an adequate graft size could be calculated from the size of the sacrificed ICA and the MCAP values. This is the first study to investigate adequate graft size in patients with complex ICA aneurysms treated using the ECA-graft-MCA bypass and therapeutic ICAO.

\section{Methods}

This study is reported based on criteria from the Strengthening the Reporting of Observational Studies in Epidemiology (STROBE) statement. ${ }^{61}$ The study protocol was approved by our institutional ethics committees. Between July 2006 and January 2016, 81 patients underwent ECA-graft-MCA bypass with therapeutic ICAO for complex ICA aneurysms at our institutions. One patient was excluded because the MCAP could not be monitored. Thus, 80 patients participated in the present study. Collected data included age, sex, smoking history, past medical history (hypertension, hypercholesterolemia, and diabetes mellitus), preoperative symptoms, size of aneurysm, aneurysm location, operative side, thrombosis or calcification of aneurysm, vessel diameters, intraoperative MCAPs (initial, after ICAO, and after release of the graft bypass), graft type, temporary occlusion time during bypasses, postoperative diffusion-weighted imaging (DWI) findings, aneurysm recurrence, follow-up period, graft patency, and outcome..$^{39,40}$ Taking into account back flow from the posterior communicating artery, the radius of the $\mathrm{C}_{2}$ portion of the ICA, which was proximal to the posterior communicating artery, was measured as the radius of the ICA. An Allen test was performed to confirm an intact palmar arch and adequate hand perfusion despite occlusion of the radial artery (RA). If an Allen test was negative, the saphenous vein (SV) was chosen as the high-flow graft.

\section{Balloon Test Occlusion}

After placing the patient in a biplane digital subtraction angiography scanner, we administered 5000 IU of intravenous heparin. A 6-Fr Flexor Shuttle guiding sheath (Cook Medical) and a 5.2-Fr Selecon MP balloon catheter (Terumo) were introduced in a coaxial fashion. To temporarily occlude the ICA, the balloon, which was positioned in the ICA between the artery's origin and the first vertebral level, was gently inflated. Stump pressure was monitored, with an abrupt decrease in pressure signaling that occlusion was complete and that balloon inflation should stop. By injecting contrast medium through the guiding sheath, we confirmed occlusion. If any change in neurological status occurred, the balloon was immediately deflated and the procedure terminated. The BTO pressure ratio was defined as the mean stump pressure divided by the mean preocclusion pressure. To correct for the difference in systemic blood pressure, each pressure reading was divided by the mean systemic blood pressure measured before or during balloon occlusion.

\section{Indication and Surgical Technique}

The ECA-graft-MCA bypass with therapeutic ICAO was performed for complex ICA aneurysms with the following indications: aneurysms with a large and complex neck not suitable for clip reconstruction, blister aneurysms, dissecting aneurysms, aneurysms with an origin of branch vessel(s) from the aneurysm sac, calcification or atherosclerotic changes of the aneurysm neck, extensive thrombosis inside the aneurysm, and recurrent aneurysms that had failed endovascular or microsurgical treatment. The superficial temporal artery (STA)-MCA bypass was performed prior to the graft-MCA anastomosis to supply blood flow to the MCA territory during graft-MCA anastomosis as a protective bypass (although whether this bypass is also protective against the LRICs is unknown). ${ }^{25}$ The STA-MCA bypass was performed not only as a backup for clamping the graft-MCA anastomosis, but also as a means of monitoring the MCAPs. ${ }^{39,40}$ Continuous MCAP monitoring through this bypass was useful to check the patency of the graft after therapeutic ICAO. ${ }^{27}$

The operative techniques for ECA-graft-MCA and STA-MCA bypasses and MCAP monitoring were recently published. ${ }^{39,40}$ The initial MCAP (iMCAP), MCAP after temporarily clamping the ICA (cMCAP), and MCAP after releasing the graft bypass (gMCAP) were monitored (Fig. 1). The MCAP ratio was defined as gMCAP divided by iMCAP. In calculating the actual MCAP ratio, each MCAP was divided by the mean systemic blood pressure measured at each MCAP reading to adjust for the difference in systemic blood pressure. After ECAgraft-MCA bypass was performed, the graft mean blood 

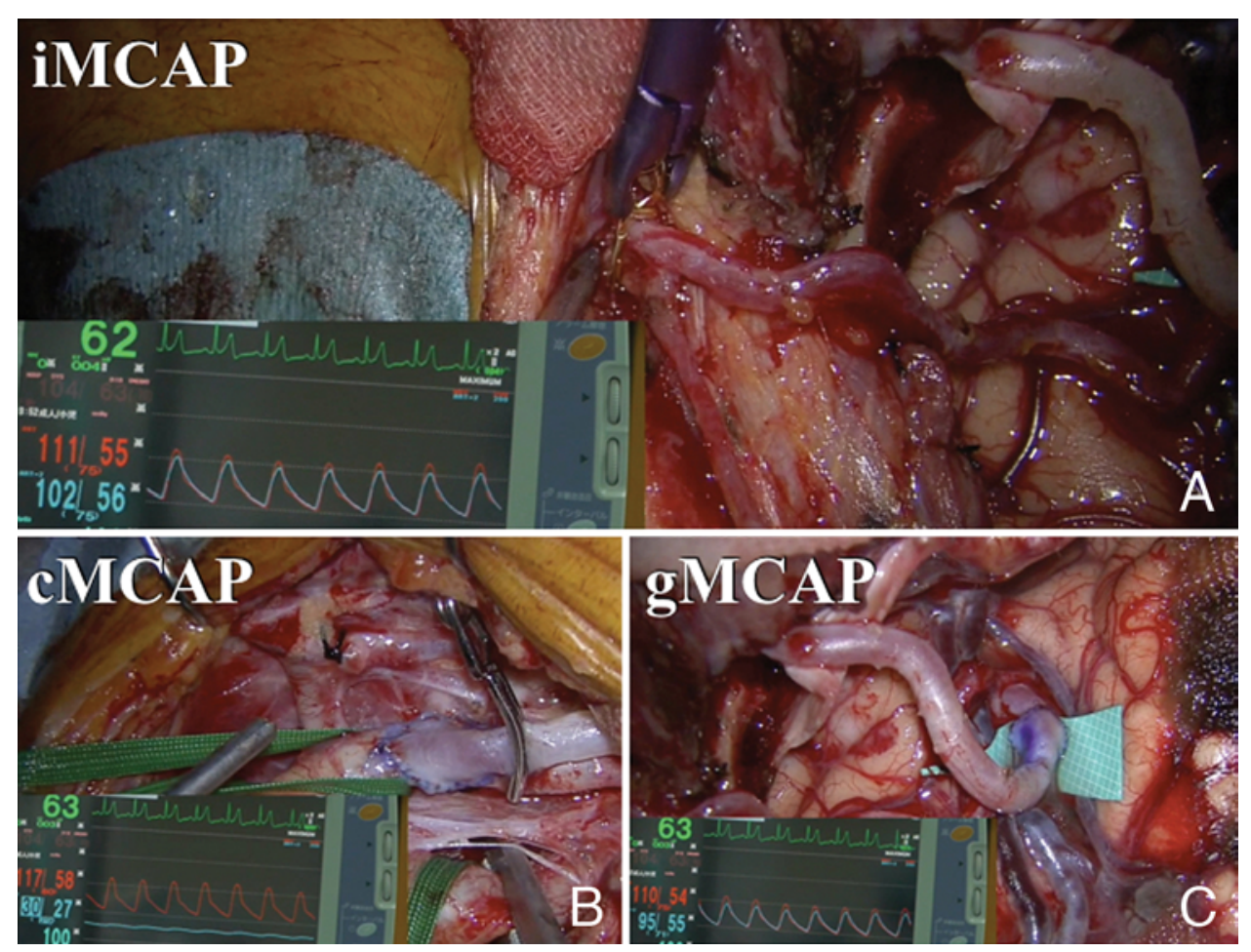

FIG. 1. Left operative side. One branch of the STA was anastomosed to the $M_{3}$ portion distal to the recipient $M_{2}$ segment. The other STA branch was immediately connected to the pressure transducer to monitor MCAP. Initial MCAP (iMCAP, A) was evaluated by clamping the STA trunk. The MCAP after clamping the ICA (CMCAP, B) and MCAP after releasing the graft bypass (gMCAP, C) were monitored. Figure is available in color online only.

flow $(\mathrm{ml} / \mathrm{min})$ was measured using surgical flowmeters (Transonic Systems).

\section{Expected MCAP Ratio}

The senior author (R. Tanikawa) hypothesized that the cerebral blood flow rate is proportional to the square of the vessel radius per Hagen-Poiseuille's law $\left(\mathrm{Q}=\pi \mathrm{r}^{2} \mathrm{v}\right),{ }^{21,49}$ where $\mathrm{Q}$ is the volume flow rate, $\mathrm{r}$ is the vessel radius, and $\mathrm{v}$ is the average flow velocity. If velocity in both the ICA and the graft is the same, the expected gMCAP would be expressed as follows:

$=$ pressure by graft blood flow + pressure by total collateral flow (Fig. 2)

$=($ pressure by ICA blood flow $)\left(\mathrm{r}_{\text {graft }} / \mathrm{r}_{\mathrm{ICA}}\right)^{2}+$ pressure by total collateral flow

where pressure by ICA blood flow $=$ iMCAP - cMCAP and pressure by total collateral flow $=\mathrm{cMCAP}$. Therefore, expected gMCAP

$$
=(\mathrm{iMCAP}-\mathrm{cMCAP})\left(\mathrm{r}_{\text {gratt }} / \mathrm{r}_{\mathrm{ICA}}\right)^{2}+\mathrm{cMCAP} .
$$

Furthermore, (expected gMCAP)/iMCAP

$$
\begin{aligned}
= & {[(\mathrm{iMCAP}-\mathrm{cMCAP}) / \mathrm{iMCAP}]\left(\mathrm{r}_{\text {gratt }} / \mathrm{r}_{\mathrm{ICA}}\right)^{2}+} \\
& (\mathrm{cMCAP} / \mathrm{iMCAP}) \\
= & (1-\mathrm{cMCAP} / \mathrm{iMCAP})\left(\mathrm{r}_{\text {gratt }} / \mathrm{r}_{\mathrm{ICA}}\right)^{2}+\mathrm{cMCAP} / \mathrm{iMCAP} .
\end{aligned}
$$

And if (expected gMCAP)/iMCAP is defined as expected
MCAP ratio and cMCAP/iMCAP is defined as $k$ (and $k>$ $0)$, then the expected MCAP ratio

$$
=(1-k)\left(\mathrm{r}_{\text {graft }} / \mathrm{r}_{\mathrm{ICA}}\right)^{2}+k .
$$

In calculating expected MCAP ratio, each MCAP was divided by the mean systemic blood pressure measured at each MCAP reading to adjust for the difference in the systemic blood pressure.

To evaluate whether the recipient vessel was adequate

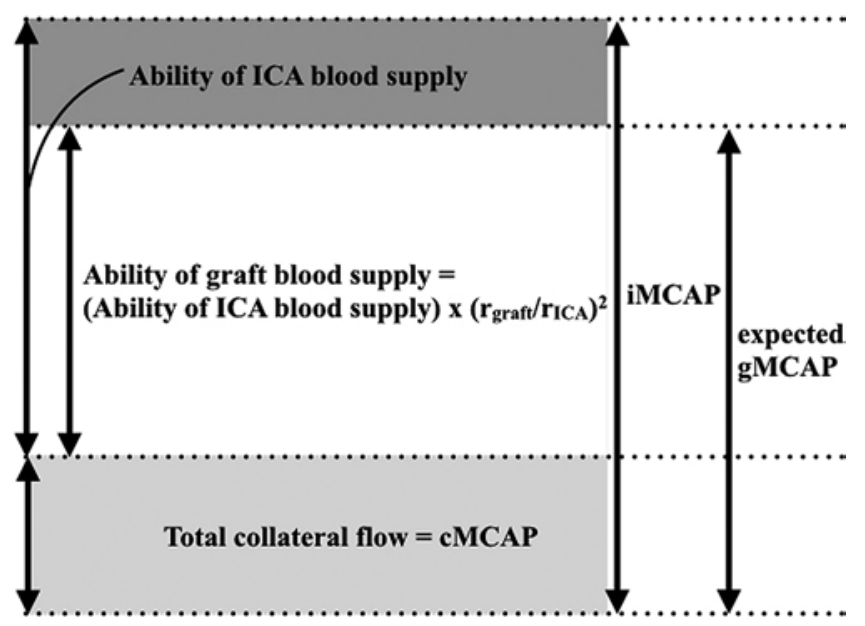

FIG. 2. Schema of the relationship between the ability of the graft to feed brain tissues without collateral circulation and MCAP. $r_{\text {graft }}=$ graft radius; $r_{I C A}=$ radius of $C_{2}$ portion of $I C A$. 
for graft, $\left(\mathrm{r}_{\mathrm{M} 2} / \mathrm{r}_{\text {graft }}\right)^{2}$ was also calculated. The $\mathrm{r}_{\text {graft }}, \mathrm{r}_{\mathrm{ICA}}$, and $\mathrm{r}_{\mathrm{M} 2}$ represent the radius of the graft, the $\mathrm{C}_{2}$ portion of the ICA, and the $\mathrm{M}_{2}$ portion of the MCA, respectively.

\section{Interrater Reliability}

Vessel diameters were measured, and the expected MCAP ratio in the 80 patients was calculated by 2 independent investigators. Interrater reliability was calculated using the intraclass correlation coefficient.

\section{Outcome}

Graft patency was confirmed using CT angiography (CTA). Postoperative DWI was performed to evaluate ischemic lesions. Low flow-related ischemic complications were defined as follows: 1) new postoperative neurological deficits and 2) ipsilateral cerebral blood flow reduction on SPECT with and without new ischemic lesions in watershed territory on DWI. The LRICs were distinguished from an aneurysm-related perforator infarction by the findings on DWI with SPECT. In aneurysm-related perforator infarctions, DWI showed no lesions in the watershed territory. The diagnosis of watershed infarction was made using the previously published template.,12,62 A SPECT study was performed in patients with new postoperative neurological deficits. Clinical outcome was evaluated according to the modified Rankin Scale (mRS), ${ }^{60}$ either by telephone interviews (conducted by H.M., independent of the primary surgeon) with the patient or family members or by physical examination of patients who were able to visit our hospital. The mRS score was evaluated at admission, discharge, and at the 6-month follow-up examination or the last hospital visit.

\section{Statistical Analysis}

Statistical analysis was performed using SPSS for Mac (version 21.0, IBM Corp.). Variables are expressed as the mean \pm standard deviation, the median (interquartile range 25 th-75th percentile), or the number of patients (\%), as appropriate. The chi-square test or Fisher exact test was applied for categorical variables, as appropriate. The normality of data was evaluated using the Shapiro-Wilk test. Normally distributed continuous variables were compared using the Student t-test, and nonnormally distributed variables were compared using the Mann-Whitney U-test.

First, we investigated the relationship between BTO pressure ratio and $\mathrm{cMCAP} / \mathrm{iMCAP}$ using the Spearman rank correlation test. Second, we evaluated the correlation between the actual and expected MCAP ratios using the Spearman rank correlation test. Third, we performed receiver operating characteristic curve analysis for continuous variables and the binary end point of LRICs. We selected cutoff points for these variables that optimized sensitivity and specificity and compared the variables of patients with and without LRICs by using the log-rank test. Finally, we performed multivariate analysis with the Cox proportional-hazards model using variables that were significantly associated with the LRICs on the log-rank test. Differences were considered significant at $p<0.05$ for a $95 \%$ confidence interval.
TABLE 1. Summary of values of MCAPs and MCAP ratios

\begin{tabular}{|c|c|}
\hline Variable & Value \\
\hline \multicolumn{2}{|c|}{ Mean MCAP, mm Hg (SD) } \\
\hline iMCAP & $71(14)$ \\
\hline cMCAP & $46(14)$ \\
\hline gMCAP & $67(12)$ \\
\hline \multicolumn{2}{|c|}{ Mean MCAP ratio (SD) } \\
\hline Actual $^{*}$ & $1.0(0.20)$ \\
\hline Expected $†$ & $1.0(0.44)$ \\
\hline BTO-expected $\ddagger$ & $1.1(0.36)$ \\
\hline \multicolumn{2}{|c|}{$\begin{array}{l}\text { * Actual MCAP ratio }=\text { gMCAP/iMCAP. } \\
\dagger \text { Expected MCAP ratio }=(1-k)\left(r_{\text {graft }} / r_{\text {ICA }}\right)^{2}+k(\text { and } k=\text { cMCAP/iMCAP and } \\
k>0) \text {. } \\
\ddagger \text { BTO-expected MCAP ratio }=\left(1-k^{\prime}\right)\left(r_{\text {graft }} / r_{\text {ICA }}\right)^{2}+k^{\prime} \text { (and } k^{\prime}=\text { [stump pres- } \\
\text { sure]/[preocclusion pressure]). }\end{array}$} \\
\hline
\end{tabular}

\section{Results}

\section{Baseline Characteristics}

The 80 patients consisted of 66 women (82\%) and 14 men $(18 \%)$, with a mean age of $59 \pm 15$ years. Clinical presentations were minor headache in 32 patients (40\%), double vision in 24 (30\%), visual field and/or visual acuity abnormality in $11(14 \%)$, postclipping or postcoiling aneurysm regrowth in $5(6.2 \%)$, subarachnoid hemorrhage in $4(5.0 \%)$, and mild hemiparalysis in $2(2.5 \%)$. When diagnostic imaging studies were performed, spontaneous cerebellar hemorrhage (1 patient) and cerebellar infarction (1 patient) were found. Median aneurysm size was $17 \mathrm{~mm}$ (range 11-24 mm). Aneurysms were located in the $\mathrm{C}_{1}(13$ [16\%]), $\mathrm{C}_{2}(18[22 \%]), \mathrm{C}_{3}(17[21 \%])$, and $\mathrm{C}_{4}(28[35 \%])$ segments of the ICA, and at the cervical ICA (dissecting aneurysm, 4 [5\%]). There were 41 aneurysms (51\%) on the left side and 39 (49\%) on the right. Calcified aneurysms were seen in 38 cases $(48 \%)$ and thrombosed aneurysms in $13(16 \%)$.

\section{Interrater Reliability}

The intraclass correlation coefficient for the expected MCAP ratio comparison between the 2 independent observers was 0.96 (95\% CI 0.93-0.97, p < 0.0001).

\section{Intraoperative and Postoperative Findings}

Mean diameters of the graft, STA, recipient $\mathrm{M}_{2}$, and $\mathrm{C}_{2}$ were $3.7 \pm 0.82,1.4 \pm 0.44,2.7 \pm 0.42$, and $4.0 \pm 0.61$ $\mathrm{mm}$, respectively. The median value for $\left(\mathrm{r}_{\mathrm{M} 2} / \mathrm{r}_{\text {graft }}\right)^{2}$ was $0.56(0.42-0.70)$. Cervical ICA ligation was performed in 43 patients (54\%) and aneurysm trapping was done in 37 $(46 \%)$.

Mean BTO pressure ratio $(0.45 \pm 0.16)$ was significantly correlated to mean cMCAP/iMCAP $(0.68 \pm 0.22 ; r=0.68$, $\mathrm{p}<0.0001)$. A summary of values for MCAPs and MCAP ratios is shown in Table 1. The mean actual MCAP ratio was significantly correlated to the mean expected MCAP ratio $(r=0.43, p<0.0001)$. If expected MCAP ratio was set up by BTO pressure ratio instead of cMCAP/iMCAP (BTO-expected MCAP ratio), then mean BTO-expected MCAP ratio was $1.1 \pm 0.36$. Expected MCAP ratio was 
TABLE 2. Analysis of factors related to LRICs

\begin{tabular}{|c|c|c|c|}
\hline \multirow[b]{2}{*}{ Variable } & \multicolumn{2}{|c|}{ LRICs } & \multirow{2}{*}{$\begin{array}{c}p \\
\text { Value }\end{array}$} \\
\hline & Yes & No & \\
\hline No. of patients & 9 & 71 & \\
\hline \multicolumn{4}{|l|}{ Clinical characteristics } \\
\hline Age $>65$ yrs & $5(56)$ & $25(35)$ & 0.24 \\
\hline Female sex & $8(89)$ & $58(82)$ & 0.59 \\
\hline Smoking & $5(56)$ & $27(38)$ & 0.34 \\
\hline Hypertension & $7(78)$ & $32(45)$ & 0.065 \\
\hline Hypercholesterolemia & $3(33)$ & $9(13)$ & 0.12 \\
\hline Diabetes mellitus & 0 & $2(2.8)$ & 0.62 \\
\hline \multicolumn{4}{|l|}{ Radiological characteristics } \\
\hline Aneurysm size $>15$ mm & $4(44)$ & $39(55)$ & 0.57 \\
\hline$\left(r_{\mathrm{M} 2} / r_{\text {graft }}\right)^{2}<0.49^{*}$ & $7(78)$ & $16(22)$ & $<0.0001$ \\
\hline Calcification of aneurysm & $5(56)$ & $33(46)$ & 0.60 \\
\hline Thrombosed aneurysm & $3(33)$ & $10(14)$ & 0.12 \\
\hline \multicolumn{4}{|l|}{ Periop characteristics } \\
\hline Mean graft flow $<120 \mathrm{ml} / \mathrm{min}$ & $1(11)$ & $18(25)$ & 0.15 \\
\hline Actual MCAP ratio $<0.80^{*}$ & $3(33)$ & $2(2.8)$ & $<0.0001$ \\
\hline Expected MCAP ratio $<0.80^{*}$ & $5(56)$ & $9(13)$ & 0.001 \\
\hline Cervical ICA ligation* & $2(22)$ & $41(58)$ & 0.049 \\
\hline Lt operative side & $7(78)$ & $32(45)$ & 0.064 \\
\hline RA graft & $8(89)$ & $51(72)$ & 0.28 \\
\hline \multicolumn{4}{|l|}{ Mean temporary occlusion time } \\
\hline STA-MCA >18 min & $4(44)$ & $20(28)$ & 0.29 \\
\hline Graft-MCA >21 min & $2(22)$ & $27(38)$ & 0.39 \\
\hline
\end{tabular}

Data expressed as the number of patients (\%).

* Variables significantly related to LRICs by the log-rank test.

significantly correlated to BTO-expected ratio $(\mathrm{r}=0.95$, $\mathrm{p}<0.0001)$. Mean blood flow of the graft was $147 \pm 52$ $\mathrm{ml} / \mathrm{min}$, and it was significantly associated with gMCAP $(\mathrm{r}=0.39, \mathrm{p}=0.006)$. The mean temporary occlusion times were $18 \pm 4.7$ minutes for STA-MCA anastomosis and 20 \pm 3.8 minutes for the graft- $\mathrm{M}_{2}$ anastomosis.

Low flow-related ischemic complications were observed in 9 patients (11\%). Symptoms of motor aphasia and/or motor weakness occurred 1-7 days after the surgical procedures. These symptoms completely resolved with medical treatment during admission. Postoperative DWI revealed ischemia in the perforating artery distribution in 11 patients $(14 \%)$ - in the anterior thalamoperforating artery distribution in 5, in the basal ganglia in 5, and in the internal capsule in 1 . Of these patients, $4(5 \%)$ had cognitive dysfunctions, 4 (5\%) were asymptomatic, and $3(3.8 \%)$ had hemiparalysis and/or aphasia.

The results of an analysis of the factors related to LRICs are shown in Table 2. An actual MCAP ratio $<0.80$, expected MCAP ratio $<0.80,\left(\mathrm{r}_{\mathrm{M} 2} / \mathrm{r}_{\text {graft }}\right)^{2}<0.49$, and cervical ICA ligation were significantly associated with LRICs according to the log-rank test. Even in the multivariate analysis, actual MCAP ratio < 0.80 , expected MCAP ratio < 0.80 , and $\left(\mathrm{r}_{\mathrm{M} 2} / \mathrm{r}_{\text {graft }}\right)^{2}<0.49$ remained significantly associated with LRICs (Table 3). Other variables showed no significant difference between patients with and without LRICs.
TABLE 3. Multivariate analyses using the Cox proportional-hazards model for LRICs

\begin{tabular}{lccc}
\hline \multicolumn{1}{c}{ Variable } & $\begin{array}{c}\text { Adjusted } \\
\mathrm{HR}\end{array}$ & $\begin{array}{c}95 \% \\
\mathrm{Cl}\end{array}$ & $\begin{array}{c}\text { Multivariable } \\
\text { Adjusted } p \text { Value }\end{array}$ \\
\hline Actual MCAP ratio $<0.8^{*}$ & 16 & $2.5-100$ & 0.003 \\
\hline Expected MCAP ratio $<0.8^{*}$ & 17 & $3.0-94$ & 0.001 \\
\hline$\left(\mathrm{r}_{\mathrm{M} 2} / \mathrm{r}_{\text {graft }}\right)^{2}<0.49^{*}$ & 64 & $4.7-85$ & 0.002 \\
\hline Cervical ICA ligation & 0.61 & $0.11-3.4$ & 0.58 \\
\hline
\end{tabular}

* Variables significantly related to LRICs.

\section{Outcome and Follow-Up}

No patient deaths were observed during the study period. Preoperative, postoperative, and long-term outcomes by mRS score are shown in Fig. 3. During a median follow-up period of 26.1 months, all RA grafts remained patent on serial 3D CTA. Saphenous vein graft occlusion occurred at 5, 6, 8, and 11 months after the surgical procedure in 4 patients. Although the STA-MCA bypasses developed well in these 4 patients, 1 had ischemic events due to SV graft occlusion.

Aneurysm regrowth occurred 162 days after the surgery in 1 patient $(1.3 \%)$, a 70 -year-old woman who had had a giant aneurysm of the left cavernous portion along with oculomotor nerve palsy. At first, she underwent ECARA-M $\mathrm{M}_{2}$ bypass with cervical ICA ligation. After aneurysm regrowth, she underwent aneurysm trapping.

\section{Discussion}

The present study demonstrated that a sufficient graft size that can supply an adequate MCAP ratio can be calculated using a formula to avoid LRICs in patients with complex ICA aneurysms treated with therapeutic ICAO.

\section{Indication for Cerebral Revascularization in Complex ICA Aneurysm Surgery}

Currently, there are 2 ways to avoid acute ischemic complications after therapeutic ICAO. One is the selective approach. Sufficient perfusion pressure appears to be present in patients with well-developed collateral circulation; therefore, such patients will remain neurologically intact just after ICAO without high-flow bypass. Balloon test occlusion is used in the selective approach to determine whether bypass surgery should be performed; however, this test can produce false-negative findings in some patients, who could subsequently develop ischemic surgical complications. In fact, $2 \%-22 \%$ of patients who pass the BTO with hypotensive challenge can experience delayed ischemic complications. ${ }^{13,34,35,52}$ Moreover, current techniques for predicting delayed ischemia after ICAO include transcranial Doppler ultrasonography, SPECT, xenon CT, perfusion CT, transcranial near-infrared spectroscopy, and perfusion MRI, although none has proved infalliable. ${ }^{15,19,22 \text {, }}$ 24,29,31,37,38,42,56,57 False-negative results leading to acute and delayed ischemic complications have been reported. ${ }^{13,23}$, 34,36,47,48,51,53,64 Furthermore, even when supplemented with cerebral blood flow studies, modern studies of ICA sacrifice after normal BTO show false-negative rates of up to 


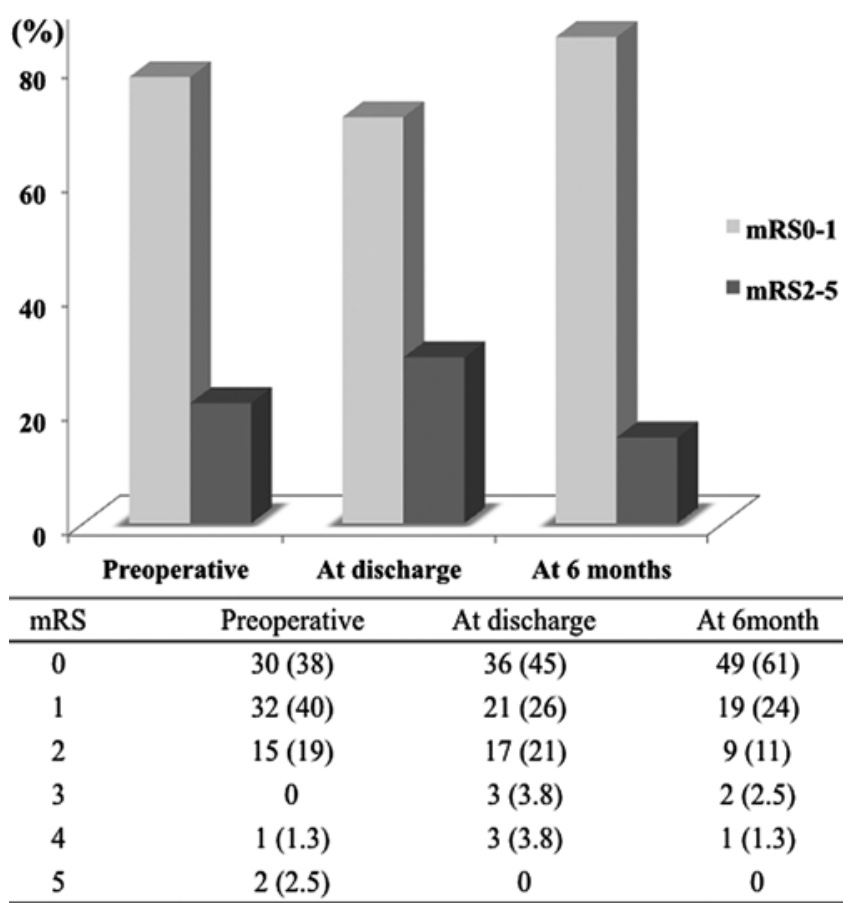

FIG. 3. Preoperative, postoperative, and long-term outcomes by mRS score. Proportions of patients with mRS Score $0-1$ before operation, at discharge, and at 6 months after surgery were $78 \%, 71 \%$, and $85 \%$, respectively.

$25 \% .^{13,34,36,47,51,53-55,65}$ Surprisingly, these rates are not much better than those in older series in which supplemental cerebral blood flow studies were not used. ${ }^{36}$

Another method of avoiding acute ischemic complications is the universal approach. In previous studies, neurological deterioration that could result in severe morbidity and death was observed in 3\%-10\% of patients who had not experienced immediate neurological symptoms after therapeutic ICAO., ${ }^{9,36}$ The short-term benefits of simple ICAO are well recognized; however, several late complications can occur, even many years after the procedure. $1,6,8,10,33$ These include delayed ischemia, ${ }^{5,52,58}$ symptoms of aneurysm growth, ${ }^{11}$ and delayed hemorrhage. ${ }^{20,43,45,46}$ Ibrahim et al. ${ }^{26}$ indicated that the most significant risk factor in de novo intracranial aneurysm development and rupture after ICAO was the change to cerebral hemodynamics. Gao et al. ${ }^{17}$ observed a $105 \%-900 \%$ increase in flow through the basilar artery after either unilateral or bilateral ligation of the common carotid artery in rabbits. This increased hemodynamic burden increases wall shear stress and initiates aneurysm formation and the likelihood of rupture. ${ }^{41} \mathrm{~A}$ review of the literature by some authors revealed 20 of 35 reported de novo intracranial aneurysms with subarachnoid hemorrhage after ICAO. ${ }^{2}$ Especially in young patients, given their longer life expectancy, the lifelong risk of the development of de novo aneurysms is higher than that in the older population. Because initial aneurysm formation in young patients is most likely a manifestation of a genetic predisposition and/or a biological phenomenon that puts the patient at higher risk for developing intracranial aneurysms ${ }^{2}$ additional hemodynamic stress should be avoided. Ibrahim et al. ${ }^{26}$ also showed that the risk for lethal subarachnoid hemorrhage was greatest in the first 10 years after ICAO. The number of deaths due to subarachnoid hemorrhage from de novo intracranial aneurysm was less in the following 2 decades and beyond, but there was still a fatality 22 years after ICAO. These authors indicated that patients undergoing ICAO for complex aneurysm treatment may represent a cohort that should be more closely monitored for de novo intracranial aneurysms, particularly in the first 20 years, as compared with patients undergoing other treatments. Preventing delayed ischemic complications and hemodynamic de novo aneurysm formation long after surgery should be as important as avoiding acute surgical complications. Taking these results into account, we believe that the ECA-graft-MCA bypass, especially one utilizing a sufficiently sized graft, is justified to avoid ischemic complications and hemodynamic stress in patients with therapeutic ICAO. ${ }^{21,22,31,35,44,45}$

\section{Rationale for Graft Selection}

Vessel sizes, including graft, recipient vessel, and sacrificed ICA, vary from patient to patient. Therefore, there has been no preoperative assurance about whether the RA or SV can supply enough blood flow to compensate for the sacrificed ICA. Thus, for the first time, we revealed that the adequate graft size can be logically calculated using a formula to obtain a sufficient MCAP ratio $(>0.80)$. The formula is based on the hypothesis that blood flow is proportional to the square of the vessel radius, per HagenPoiseuille's law, ${ }^{21,49}$ and that pressure by graft blood flow can be represented as (pressure by ICA blood flow) $\left(\mathrm{r}_{\text {graft }} /\right.$ $\left.\mathrm{r}_{\mathrm{ICA}}\right)^{2}$. Although significance was not very strong, the expected MCAP ratio was correlated to the actual MCAP ratio. It may support the validity of the formula. Based on the formula, small RA and SV grafts may be insufficient, and a large STA may be a high-flow graft to a sacrificed ICA. In addition, a BTO pressure ratio was correlated to $k$ value, and BTO-expected MCAP ratio was correlated to expected MCAP ratio. Therefore, an adequate graft can be calculated before the operation by using the following formula for expected MCAP ratio:

$$
\begin{aligned}
& =(1-\mathrm{BTO} \text { pressure ratio })\left(\mathrm{r}_{\text {graft }} / \mathrm{r}_{\mathrm{ICA}}\right)^{2}+(\mathrm{BTO} \text { pressure } \\
& \quad \text { ratio }) \geq 0.80 .
\end{aligned}
$$

Therefore,

$$
\begin{aligned}
& \left(\mathrm{r}_{\text {graft }} / \mathrm{r}_{\mathrm{ICA}}\right)^{2} \geq(0.80-\mathrm{BTO} \text { pressure ratio }) /(1-\mathrm{BTO} \\
& \text { pressure ratio }) .
\end{aligned}
$$

Therefore,

$$
\begin{aligned}
& \mathrm{r}_{\text {graft }} \geq \\
& \quad \sqrt{(0.80-\text { BTO pressure ratio }) /(1-B T O \text { pressure ratio })} \\
& \quad \times \mathrm{r}_{\mathrm{ICA}}
\end{aligned}
$$

(and $r_{\text {graft }} \geq 0$ ).

Taking into account only cerebral blood flow just after the operation, if $r_{\text {graft }}$ shows 0 , graft use turns out to be redundant in this formula. However, as stated above, ECAgraft-MCA bypass may be needed to avoid delayed ischemic complications and long-term hemodynamic stress. 
During the follow-up periods, all RA grafts were patent and the results were comparable or superior to those in previous studies. . $^{18,28,30,44}$ On the other hand, in 4 patients who were treated with an ECA-SV-M ${ }_{2}$ bypass, the SV grafts occluded in the chronic phase. We speculate that the possible mechanisms of SV graft failure were as follows: 1) the SV is not a vessel physiologically intended to convey arterial flow, and the lumen caliber more closely approximates that of the $\mathrm{M}_{2}$ portion, which is our usual recipient vessel; and 2) the SV has a uniform intimal wall that lacks the valves and varices of venous grafts. Therefore, if an Allen test is positive and an RA has a sufficient diameter, as evaluated using the formula, the RA may be a better candidate for the high-flow graft.

As regards recipient selection, the present study indicated that an inadequate recipient artery size, which caused LRICs due to a "narrowed bottleneck," led to an insufficient blood supply, even if the graft was larger. Therefore, the MCA portion, which has a sufficient diameter, should be selected for the graft-MCA anastomosis.

\section{Study Limitations}

Some limitations of this study should be mentioned. First, because the number of patients and outcomes of interest (that is, LRICs) were small, the $95 \%$ confidence intervals of the odds ratios became large. Despite the small numbers, however, the association between the factors and LRICs was significant, even in the Cox proportional-hazards model.

Second, the MCAP measurement requires validation, considering that the territory supplied by the ECA-graftMCA bypass may have different total vascular resistances depending on the anatomy. Inherent variations in the STA anatomy itself and possible vessel spasm during the procedure add additional variables that are time variant and not normalized or calibrated if one argues that there is intrapatient self-consistency of such physiology. However, the MCAP measurement could be continuously monitored and be a surrogate marker for LRICs, although graft blood flow measured by Transit flowmeter was not associated with the LRICs. In addition, if a sufficient MCAP ratio is not found intraoperatively, graft troubles such as kinking, twisting, and thrombosis should be suspected and graft revision should be performed. Actually, MCAP monitoring detected kinking or twisting of the graft in 7 patients (8.8\%), which led to immediate revisions of the anastomosis during surgery. In this regard, we thought that the graft blood flow might have been influenced by the graft kinking and/or distortion, especially en route from the cranium to the neck, and that it might not reflect the accurate blood flow. If there are stenotic lesions, graft blood flow appears to be fast. On the other hand, gMCAP decreases, reflecting the lower graft blood volume. Because MCAP was measured distal to the graft- $\mathrm{M}_{2}$ anastomosis, it was more important for evaluating the cerebral perfusion given the difference in cerebral vascular resistance.

Third, the treatment strategy of ECA-graft-MCA bypass with MCAP monitoring for complex ICA aneurysms may be a complicated and rather impractical method. In addition, the time and risk associated with the construction of an STA-MCA bypass is a major limitation. However, the technique could be achieved by a combination of established neurosurgical techniques: sylvian fissure dissection and extracranial to intracranial bypass. Furthermore, continuous MCAP monitoring is easily performed and potentially useful because both neurosurgeons and anesthesiologists can respond quickly to a deterioration in hemodynamics during the anastomosis, dural closure, and bone flap fixation.

Fourth, it is unclear whether cerebral blood flow is proportional to the square of the vessel radius per HagenPoiseuille's law or whether the velocity in both the ICA and the graft is the same. Given the limited number of patients with complex ICA aneurysms who needed to be treated with ECA-graft-MCA bypass and therapeutic ICAO, we were unable to prove the hypothesis.

Fifth, intraoperative evaluation of bypass patency can be performed in a variety of ways beyond simple visual inspection and palpation of pulse. These include routine intraoperative angiography, microvascular Doppler assessment, ${ }^{3}$ thermal diffusion flow probe,,$^{32}$ or fluorescent dye (indocyanine green) angiography. ${ }^{50,63}$ However, these methods do not provide quantitative assessment of flow in the bypass and are therefore less definitive in confirming the adequacy of the revascularization strategy.

Sixth, there are other tests of flow dynamics that can be performed prior to the BTO (for example, MRI time-offlight quantitative flow measurements) and acetazolamide challenges that can further increase the accuracy of the BTO. Charbel et al. ${ }^{9}$ demonstrated the efficacy of a novel simulation technique, the sector model, in the patient-specific prediction of clinical outcomes accompanying endovascular vessel occlusion. They showed that phase-contrast MR angiography measurements of flow and BTO predictions made using cerebral blood flow modeling were closely related to the clinical outcome of BTO with a hypotensive challenge. The advantages of flow measurements are that they are much simpler and do not require construction of an STA-MCA bypass to make the measurements. However, only 16 patients were included in that study, and even in their novel model, $1(10 \%)$ of 10 patients who passed the BTO experienced ischemia ipsilateral to the occlusion and died several days after ICAO. Moreover, the authors evaluated only the immediate results and did not investigate longterm hemodynamic stress and de novo aneurysm formation.

Finally, although measurements of vessel diameter on the axial volume data of 3D CTA can differ from intraoperative measurements, the extent of the difference between radiological vessel diameters and actual vessel diameters remains unknown. Therefore, further studies are warranted to clarify results of the present study.

\section{Conclusions}

Data in the present study showed that it was important to select an adequate graft to achieve a sufficient MCAP ratio to avoid LRICs and that the adequate graft size could be determined using a formula consisting of MCAPs and the size of the sacrificed ICA. Because the development of collateral circulation and vessel sizes are variable from patient to patient, the formula may provide a rationale for graft selection in patients with complex ICA aneurysms who need therapeutic ICAO. 


\section{References}

1. Arambepola PK, McEvoy SD, Bulsara KR: De novo aneurysm formation after carotid artery occlusion for cerebral aneurysms. Skull Base 20:405-408, 2010

2. Arnaout OM, Rahme RJ, Aoun SG, Daou MR, Batjer HH, Bendok BR: De novo large fusiform posterior circulation intracranial aneurysm presenting with subarachnoid hemorrhage 7 years after therapeutic internal carotid artery occlusion: case report and review of the literature. Neurosurgery 71:E764-E771, 2012

3. Badie B, Lee FT Jr, Pozniak MA, Strother CM: Intraoperative sonographic assessment of graft patency during extracranial-intracranial bypass. AJNR Am J Neuroradiol 21:1457-1459, 2000

4. Barker DW, Jungreis CA, Horton JA, Pentheny S, Lemley T: Balloon test occlusion of the internal carotid artery: change in stump pressure over 15 minutes and its correlation with xenon CT cerebral blood flow. AJNR Am J Neuroradiol 14:587-590, 1993

5. Barnett HJ: Delayed cerebral ischemic episodes distal to occlusion of major cerebral arteries. Neurology 28:769-774, 1978

6. Bendok BR, Murad A, Getch CC, Batjer HH: Failure of a saphenous vein extracranial-intracranial bypass graft to protect against bilateral middle cerebral artery ischemia after carotid artery occlusion: case report. Neurosurgery 45:367-371, 1999

7. Bogousslavsky J, Regli F: Unilateral watershed cerebral infarcts. Neurology 36:373-377, 1986

8. Briganti F, Cirillo S, Caranci F, Esposito F, Maiuri F: Development of "de novo" aneurysms following endovascular procedures. Neuroradiology 44:604-609, 2002

9. Charbel FT, Zhao M, Amin-Hanjani S, Hoffman W, Du X, Clark ME: A patient-specific computer model to predict outcomes of the balloon occlusion test. J Neurosurg 101:977988,2004

10. Clark WC, Ray MW: Contralateral intracranial aneurysm formation as a late complication of carotid ligation. Surg Neurol 18:458-462, 1982

11. Cuatico W, Cook AW, Tyshchenko V, Khatib R: Massive enlargement of intracranial aneurysms following carotid ligation. Arch Neurol 17:609-613, 1967

12. Damasio H: A computed tomographic guide to the identification of cerebral vascular territories. Arch Neurol 40:138142,1983

13. Dare AO, Chaloupka JC, Putman CM, Fayad PB, Awad IA: Failure of the hypotensive provocative test during temporary balloon test occlusion of the internal carotid artery to predict delayed hemodynamic ischemia after therapeutic carotid occlusion. Surg Neurol 50:147-156, 1998

14. Dyste GN, Beck DW: De novo aneurysm formation following carotid ligation: case report and review of the literature. Neurosurgery 24:88-92, 1989

15. Eckert B, Thie A, Carvajal M, Groden C, Zeumer H: Predicting hemodynamic ischemia by transcranial Doppler monitoring during therapeutic balloon occlusion of the internal carotid artery. AJNR Am J Neuroradiol 19:577-582, 1998

16. Fujiwara S, Fujii K, Fukui M: De novo aneurysm formation and aneurysm growth following therapeutic carotid occlusion for intracranial internal carotid artery (ICA) aneurysms. Acta Neurochir (Wien) 120:20-25, 1993

17. Gao L, Hoi Y, Swartz DD, Kolega J, Siddiqui A, Meng H: Nascent aneurysm formation at the basilar terminus induced by hemodynamics. Stroke 39:2085-2090, 2008

18. Gobble RM, Hoang H, Jafar J, Adelman M: Extracranialintracranial bypass: resurrection of a nearly extinct operation. J Vasc Surg 56:1303-1307, 2012

19. Graves VB, Perl J II, Strother CM, Wallace RC, Kesava PP, Masaryk TJ: Endovascular occlusion of the carotid or vertebral artery with temporary proximal flow arrest and microcoils: clinical results. AJNR Am J Neuroradiol 18:1201-1206, 1997

20. Gurdjian ES, Lindner DW, Thomas LM: Experiences with ligation of the common carotid artery for treatment of aneurysms of the internal carotid artery. J Neurosurg 23:311318,1965

21. Hagen CHL: Uber die Bewegung des Wassers in engen cylindrischen Rohren. Annalen der Physik und Chemie 42:423-442, 1839

22. Hetzel A, von Reutern G, Wernz MG, Droste DW, Schumacher M: The carotid compression test for therapeutic occlusion of the internal carotid artery. Comparison of angiography with transcranial Doppler sonography. Cerebrovasc Dis 10:194-199, 2000

23. Higashida RT, Halbach VV, Dowd CF, Barnwell SL, Hieshima GB: Intracranial aneurysms: interventional neurovascular treatment with detachable balloons-results in 215 cases. Radiology 178:663-670, 1991

24. Hoeffner EG, Case I, Jain R, Gujar SK, Shah GV, Deveikis JP, et al: Cerebral perfusion CT: technique and clinical applications. Radiology 231:632-644, 2004

25. Hongo K, Horiuchi T, Nitta J, Tanaka Y, Tada T, Kobayashi $\mathrm{S}$ : Double-insurance bypass for internal carotid artery aneurysm surgery. Neurosurgery 52:597-602, 2003

26. Ibrahim TF, Jahromi BR, Miettinen J, Raj R, Andrade-Barazarte $\mathrm{H}$, Goehre F, et al: Long-term causes of death and excess mortality after carotid artery ligation. World Neurosurg 90:116-122, 2016

27. Ishikawa T, Kamiyama H, Kobayashi N, Tanikawa R, Takizawa K, Kazumata K: Experience from "double-insurance bypass." Surgical results and additional techniques to achieve complex aneurysm surgery in a safer manner. Surg Neurol 63:485-490, 2005

28. Ishishita Y, Tanikawa R, Noda K, Kubota H, Izumi N, Katsuno M, et al: Universal extracranial-intracranial graft bypass for large or giant internal carotid aneurysms: techniques and results in 38 consecutive patients. World Neurosurg 82:130-139, 2014

29. Jain R, Hoeffner EG, Deveikis JP, Harrigan MR, Thompson BG, Mukherji SK: Carotid perfusion CT with balloon occlusion and acetazolamide challenge test: feasibility. Radiology 231:906-913, 2004

30. Kalani MY, Ramey W, Albuquerque FC, McDougall CG, Nakaji P, Zabramski JM, et al: Revascularization and aneurysm surgery: techniques, indications, and outcomes in the endovascular era. Neurosurgery 74:482-498, 2014

31. Kaminogo M, Ochi M, Onizuka M, Takahata H, Shibata S: An additional monitoring of regional cerebral oxygen saturation to HMPAO SPECT study during balloon test occlusion. Stroke 30:407-413, 1999

32. Kubo Y, Ogasawara K, Tomitsuka N, Otawara Y, Kakino S, Ogawa A: Revascularization and parent artery occlusion for giant internal carotid artery aneurysms in the intracavernous portion using intraoperative monitoring of cerebral hemodynamics. Neurosurgery 58:43-50, 2006

33. Kurokawa T, Harada K, Ishihara H, Fujisawa H, Kato S, Kajiwara K, et al: De novo aneurysm formation on middle cerebral artery branches adjacent to the anastomotic site of superficial temporal artery-middle cerebral artery bypass surgery in two patients: technical case report. Neurosurgery 61 (5 Suppl 2):E297-E298, 2007

34. Larson JJ, Tew JM Jr, Tomsick TA, van Loveren HR: Treatment of aneurysms of the internal carotid artery by intravascular balloon occlusion: long-term follow-up of 58 patients. Neurosurgery 36:26-30, 1995

35. Lawton MT, Hamilton MG, Morcos JJ, Spetzler RF: Revascularization and aneurysm surgery: current techniques, indications, and outcome. Neurosurgery 38:83-94, 1996

36. Linskey ME, Jungreis CA, Yonas H, Hirsch WL Jr, Sekhar 
LN, Horton JA, et al: Stroke risk after abrupt internal carotid artery sacrifice: accuracy of preoperative assessment with balloon test occlusion and stable xenon-enhanced CT. AJNR Am J Neuroradiol 15:829-843, 1994

37. Marshall RS, Lazar RM, Young WL, Solomon RA, Joshi $\mathrm{S}$, Duong DH, et al: Clinical utility of quantitative cerebral blood flow measurements during internal carotid artery test occlusions. Neurosurgery 50:996-1005, 2002

38. Mathis JM, Barr JD, Jungreis CA, Yonas H, Sekhar LN, Vincent $\mathrm{D}$, et al: Temporary balloon test occlusion of the internal carotid artery: experience in 500 cases. AJNR Am J Neuroradiol 16:749-754, 1995

39. Matsukawa H, Tanikawa R, Kamiyama H, Tsuboi T, Noda $\mathrm{K}$, Ota N, et al: Risk factors for low-flow related ischemic complications and neurological worsening in patients with complex internal carotid artery aneurysm treated by EC-IC high-flow bypass. World Neurosurg 85:49-55, 2016

40. Matsukawa H, Tanikawa R, Kamiyama H, Tsuboi T, Noda $\mathrm{K}$, Ota N, et al: Risk factors for neurological worsening and symptomatic watershed infarction in internal carotid artery aneurysm treated by extracranial-intracranial bypass using radial artery graft. J Neurosurg 125:239-246, 2016

41. Meng H, Wang Z, Hoi Y, Gao L, Metaxa E, Swartz DD, et al: Complex hemodynamics at the apex of an arterial bifurcation induces vascular remodeling resembling cerebral aneurysm initiation. Stroke 38:1924-1931, 2007

42. Michel E, Liu H, Remley KB, Martin AJ, Madison MT, Kucharczyk J, et al: Perfusion MR neuroimaging in patients undergoing balloon test occlusion of the internal carotid artery. AJNR Am J Neuroradiol 22:1590-1596, 2001

43. Miller JD, Jawad K, Jennett B: Safety of carotid ligation and its role in the management of intracranial aneurysms. J Neurol Neurosurg Psychiatry 40:64-72, 1977

44. Mohit AA, Sekhar LN, Natarajan SK, Britz GW, Ghodke B: High-flow bypass grafts in the management of complex intracranial aneurysms. Neurosurgery 60 (2 Suppl 1): ONS105ONS123, 2007

45. Niiro M, Shimozuru T, Nakamura K, Kadota K, Kuratsu J: Long-term follow-up study of patients with cavernous sinus aneurysm treated by proximal occlusion. Neurol Med Chir (Tokyo) 40:88-97, 2000

46. Nishioka H: Report on the cooperative study of intracranial aneurysms and subarachnoid hemorrhage. Section VII. I. Evaluation of the conservative management of ruptured intracranial aneurysms. J Neurosurg 25:574-592, 1966

47. Origitano TC, al-Mefty O, Leonetti JP, DeMonte F, Reichman $\mathrm{OH}$ : Vascular considerations and complications in cranial base surgery. Neurosurgery 35:351-363, 1994

48. Pancucci G, Potts MB, Rodríguez-Hernández A, Andrade H, Guo L, Lawton MT: Rescue bypass for revascularization after ischemic complications in the treatment of giant or complex intracranial aneurysms. World Neurosurg 83:912-920, 2015

49. Poiseuille JLM: Recherches experimentales sur le mouvement des liquides dans les tubes de tres petits diametres. Mem Acad R Sci Instit France 9:433-544, 1846

50. Raabe A, Beck J, Gerlach R, Zimmermann M, Seifert V: Near-infrared indocyanine green video angiography: a new method for intraoperative assessment of vascular flow. Neurosurgery 52:132-139, 2003

51. Rathore YS, Chandra PS, Kumar R, Singh M, Sharma MS, Suri A, et al: Monitored gradual occlusion of the internal carotid artery followed by ligation for giant internal carotid artery aneurysms. Neurol India 60:174-179, 2012

52. Roski RA, Spetzler RF, Nulsen FE: Late complications of carotid ligation in the treatment of intracranial aneurysms. $\mathbf{J}$ Neurosurg 54:583-587, 1981

53. Segal DH, Sen C, Bederson JB, Catalano P, Sacher M, Stollman AL, et al: Predictive value of balloon test occlusion of the internal carotid artery. Skull Base Surg 5:97-107, 1995
54. Sekhar LN, Patel SJ: Permanent occlusion of the internal carotid artery during skull-base and vascular surgery: is it really safe? Am J Otol 14:421-422, 1993

55. Shimizu H, Matsumoto Y, Tominaga T: Parent artery occlusion with bypass surgery for the treatment of internal carotid artery aneurysms: clinical and hemodynamic results. Clin Neurol Neurosurg 112:32-39, 2010

56. Sorteberg A, Bakke SJ, Boysen M, Sorteberg W: Angiographic balloon test occlusion and therapeutic sacrifice of major arteries to the brain. Neurosurgery 63:651-661, 2008

57. Sugawara Y, Kikuchi T, Ueda T, Nishizaki M, Nakata S, Mochizuki T, et al: Usefulness of brain SPECT to evaluate brain tolerance and hemodynamic changes during temporary balloon occlusion test and after permanent carotid occlusion. J Nucl Med 43:1616-1623, 2002

58. Swearingen B, Heros RC: Common carotid occlusion for unclippable carotid aneurysms: an old but still effective operation. Neurosurgery 21:288-295, 1987

59. Timperman PE, Tomsick TA, Tew JM Jr, van Loveren HR: Aneurysm formation after carotid occlusion. AJNR Am J Neuroradiol 16:329-331, 1995

60. van Swieten JC, Koudstaal PJ, Visser MC, Schouten HJ, van Gijn J: Interobserver agreement for the assessment of handicap in stroke patients. Stroke 19:604-607, 1988

61. von Elm E, Altman DG, Egger M, Pocock SJ, Gøtzsche PC, Vandenbroucke JP: The Strengthening the Reporting of Observational Studies in Epidemiology (STROBE) statement: guidelines for reporting observational studies. Lancet 370:1453-1457, 2007

62. Weiller C, Ringelstein EB, Reiche W, Buell U: Clinical and hemodynamic aspects of low-flow infarcts. Stroke 22:11171123, 1991

63. Woitzik J, Horn P, Vajkoczy P, Schmiedek P: Intraoperative control of extracranial-intracranial bypass patency by nearinfrared indocyanine green videoangiography. J Neurosurg 102:692-698, 2005

64. Zhu W, Tian YL, Zhou LF, Song DL, Xu B, Mao Y: Treatment strategies for complex internal carotid artery (ICA) aneurysms: direct ICA sacrifice or combined with extracranialto-intracranial bypass. World Neurosurg 75:476-484, 2011

65. Zhu XL, Ni CF, Liu YZ, Jin YH, Zou JW, Chen L: Treatment strategies and indications for interventional management of pseudoaneurysms. Chin Med J (Engl) 124:1784-1789, 2011

\section{Disclosures}

The authors report no conflict of interest concerning the materials or methods used in this study or the findings specified in this paper.

\section{Author Contributions}

Conception and design: Matsukawa, Miyata, Tsuboi, Noda, Ota, Kamiyama, Tanikawa. Acquisition of data: Matsukawa, Miyata, Tsuboi, Noda, Ota, Kamiyama, Tanikawa. Analysis and interpretation of data: Matsukawa, Kamiyama, Tanikawa. Drafting the article: Matsukawa. Critically revising the article: Matsukawa, Tanikawa. Reviewed submitted version of manuscript: Matsukawa. Approved the final version of the manuscript on behalf of all authors: Matsukawa. Statistical analysis: Matsukawa, Takahashi. Administrative/technical/material support: Miyata, Tsuboi, Noda, Takeda, Tokuda, Kamiyama, Tanikawa. Study supervision: Ota, Kamiyama, Tanikawa.

\section{Correspondence}

Hidetoshi Matsukawa, Department of Neurosurgery, Stroke Center, Teishinkai Hospital, 3-1, Higashi 1, Kita 33, Higashi-ku, Sapporo, Hokkaido 065-0033, Japan. email: nowornever1982@ gmail.com. 